\title{
Self-concept and body image of people living with lupus: A systematic review
}

\author{
Larissa Rodrigues $^{1}$ (D) | Maria M. F. Sim-Sim² (D) | Luis Sousa ${ }^{2}$ (D) | \\ Débora B. Faria-Schützer ${ }^{1}$ (D) | Fernanda G. Surita ${ }^{3}$
}

\author{
${ }^{1}$ School of Medical Science, University of \\ Campinas (UNICAMP), Campinas, Brazil \\ ${ }^{2}$ Nursing Department, Comprehensive \\ Health Research Center (CHRC)., University \\ of Evora (UE), Evora, Portugal \\ ${ }^{3}$ Department Obstetrics and Gynecology, \\ School of Medical Science, University of \\ Campinas (UNICAMP), Campinas, Brazil

\section{Correspondence} \\ Fernanda G. Surita, Department Obstetrics \\ and Gynecology, School of Medical Science \\ University of Campinas (UNICAMP), \\ Alexander Fleming 101 - Campinas SP, \\ Brazil. \\ Email: surita@unicamp.br
}

Funding information

This work was supported by Coordination of Improvement of Higher Education Personnel - Brazil (CAPES) no. 88881.188510/2018-01.

\begin{abstract}
Aim: To summarize existing evidence regarding body image in patients with systemic lupus erythematosus, with the following considerations: (a) the perceptions patients have of their body changes; (b) how patients cope with changes in their body; (c) and what their perceptions are of body changes.

Method: A systematic review of literature integrating quantitative and qualitative studies. We searched databases (PubMed, CINAHL, Embase, SCOPUS, the Web of Science, Medline, Medline Complete, and Academic Search Premier) and publications from 2010 to 2020 with "Systemic Lupus Erythematosus" AND "Self-Concept" OR "Body Image" AND "Woman" as medical subheading terms. The studies included were subjected to a thematic content analysis, which allowed subjective interpretation of data through a systematic classification process for coding themes or patterns. Results: We identified 647 studies, of which 22 were analyzed in this study. Our results indicate that changes in the body image of people with lupus and their perception are issues that must be treated as characteristics of the disease; therefore, they need to receive the same attention as is given to physical disabilities and pain. The analysis identified 3 thematic categories: (a) depression and anxiety associated with body changes (hair loss, weight gain); (b) body image reflecting the disease; and (c) confrontations and interventions to promote acceptance and adaptation to the new image.
\end{abstract}

Conclusions: The dimensions of self-concept and body image are essential for assessing the quality of life of individuals with lupus. The formation of a adjusted selfconcept can be managed by health professionals supporting these people.

\section{KEYWORDS}

body dissatisfaction, body image, self-concept, systematic review, systemic lupus erythematosus 


\section{1 | INTRODUCTION}

Body image $(\mathrm{BI})$ refers to the internal representation and perceptions of appearance and behavior and attitudes held by an individual. $^{1,2}$ The attitudinal dimensions of $\mathrm{BI}$, which include the beliefs and values of the individual, ${ }^{1,3}$ can be explored from many perspectives. The perceptual dimensions of $\mathrm{BI}$ are focused on the individual's precise judgments of their size, weight, and body shape. ${ }^{1}$ Some aspects of $\mathrm{BI}$ are associated with efforts made to control or change appearance, adopt behaviors to avoid being judged by others, ${ }^{1}$ and achieve a desired or idealized body. ${ }^{1,4}$

BI disorders can take many forms, including extreme dissatisfaction with appearance and compulsory checking and fear of judgment of appearance. ${ }^{2}$ These disorders have been consistently associated with psychological consequences, ${ }^{5}$ including depressive symptoms ${ }^{6}$ and impaired self-esteem. ${ }^{7}$ BI disturbance (BID) is defined as the distortion of perceptions or cognition related to body weight or shape. ${ }^{8}$ BID plays an important role in anxiety/depression and reduces quality of life (QoL).,10

$\mathrm{BI}$ reflects external appearance and is separate from selfconcept, which refers to an individual's view of oneself as a person. In individuals with systemic lupus erythematosus (SLE), self-concept can remain positive, even when $\mathrm{BI}$ is negative. ${ }^{11}$

SLE is a multisystemic disease that can alter body appearance. Its rate of incidence is 9-240 cases/100 000 people and is prevalent in women in reproductive age (the female-to-male ratio is 9:1). ${ }^{12,13}$ The disease has a different presentation in different individuals, with variable levels of severity. ${ }^{14}$

In general, clinical manifestations of SLE involve several organs, including the skin, kidneys, lungs, heart, and central nervous system. Affected organs and systems suffer from disease sequelae, and periods of remission may occur without clinical manifestations. ${ }^{13,15}$ SLE manifestations include spots, flushing, and skin rashes, especially on the face, joint changes, hair loss, and weight gain, ${ }^{13}$ which make the disease apparent and can cause changes in BI.

Therefore, this review focuses on the changes and adaptations that occur in the $\mathrm{BI}$ of people with SLE as primary interest and in their self-concept as secondary interest and is aimed at summarizing existing evidence regarding $\mathrm{BI}$ and self-concept in patients with SLE, with the following considerations: (1) the perceptions patients have of their body changes; (2) how patients cope with changes in their body; (3) and what their perceptions are of body changes. To fulfill these objectives, we will conduct an analysis of both quantitative and qualitative studies.

\section{2 | METHODS}

\section{1 | Protocol and registration}

This review was registered in PROSPERO, under number CRD42019126613. To design the study, the Preferred Reporting Items for Systematic Reviews and Meta-Analyses (PRISMA) checklist was used. ${ }^{16}$

\section{2 | Inclusion criteria}

\subsection{1 | Types of patients and conditions}

Adult patients (more than 18 years old) diagnosed with SLE, according to the European League Against Rheumatism (EULAR) and the American College of Rheumatology (ACR), ${ }^{17}$ were included in the study. The selected studies had to include self-concept and/or $\mathrm{BI}$ subjects.

\subsection{2 | Types of outcomes}

Outcomes are reported for the participants' experience or perception of the influence of SLE on their own persons: the patient's perception of their body; how they interpret and cope with their $\mathrm{Bl}$; what kind of symptoms are associated with how the patient feels; and how they see or conceptualize their self.

\subsection{3 | Types of studies}

Published peer-reviewed journal articles were considered in this review. Qualitative or quantitative designed observational studies (descriptive cross-sectional analyses, case-control analyses, and cohort analyses) and designed experimental studies (randomized and non-randomized) were included. There was no geographical restriction, and studies published in English, Spanish, French, or Portuguese were eligible. The articles were published between 2010 and 2020. We considered for inclusion studies focused on the issue of $\mathrm{BI}$ and those that made evident the relationship between $\mathrm{BI}$ and other issues, such as QoL as a primary interest, or even selfconcept as a secondary interest. Methodological studies for instrument validation, case studies or case reports, and literature reviews were excluded.

\section{3 | Search strategy}

This systematic review asked the research question what the $\mathrm{BI}$ is of people living with lupus. A literature search was performed in February 2019 and updated in June 2020, and used the following electronic databases: US National Library of Medicine - National Institutes of Health (PubMed), Cumulative Index to Nursing and Allied Health Literature (CINAHL), Excerpta Medica (Embase), SCOPUS, the Web of Science, Medline, Medline Complete, and Academic Search Premier. A manual search of lists of selected articles supplemented the electronic search. All studies selected were electronically available.

Two authors (LR and MSS) performed the search. The medical subheading $(\mathrm{MeSH})$ terms used were "Systemic Lupus Erythematosus" AND "Self-Concept" OR "Body Image" AND "Woman". 


\section{4 | Study records}

A database was created with the free software EndNote to manage the publications searched. For the exclusion process, the covidence. org tool for organizing systematic reviews (available at https://www. covidence.org) was used.

Two reviewers (LR and MSS) independently screened titles and abstracts. At the end of this selection phase, the 2 reviewers discussed cases of disagreement. If there was doubt about eligibility, the article was included until the full textual analysis phase. If doubt remained, a third reviewer (LMS) provided an opinion on the eligibility of the text. The search process is summarized in Figure 1.

\section{5 | Bias assessment}

Assessments of the quality of articles were based on checklists developed by Joanna Briggs Institute (JBI) for quasi-experimental, cross-sectional, and qualitative research, ${ }^{18}$ available at The System for the Unified Management, Assessment and Review of Information
(SUMMARI). Two authors (LR and MSS) performed the assessments. Disagreements were managed to reach consensus through analysis and discussion with a third author (LMS). The level of evidence provided by the studies was evaluated according to the JBI Model of Evidence Based Healthcare. ${ }^{19}$

\section{6 | Data analysis}

The studies were subjected to thematic content analysis, which allows data to be interpreted through a systematic classification process for coding themes or patterns. ${ }^{18}$ To enable analysis of quantitative and qualitative studies, goal aggregation ${ }^{20}$ was carried out using the following procedures: the high points of the qualitative studies were raised and themes were generated and codified, ${ }^{18}$ and the variables in quantitative studies were transformed into similar themes and also codified. ${ }^{20}$ The analysis culminated in a synthesis of the content, with construction of thematic categories for organization and presentation of the meta-aggregation material. ${ }^{21}$
FIGURE 1 Study search flow diagram

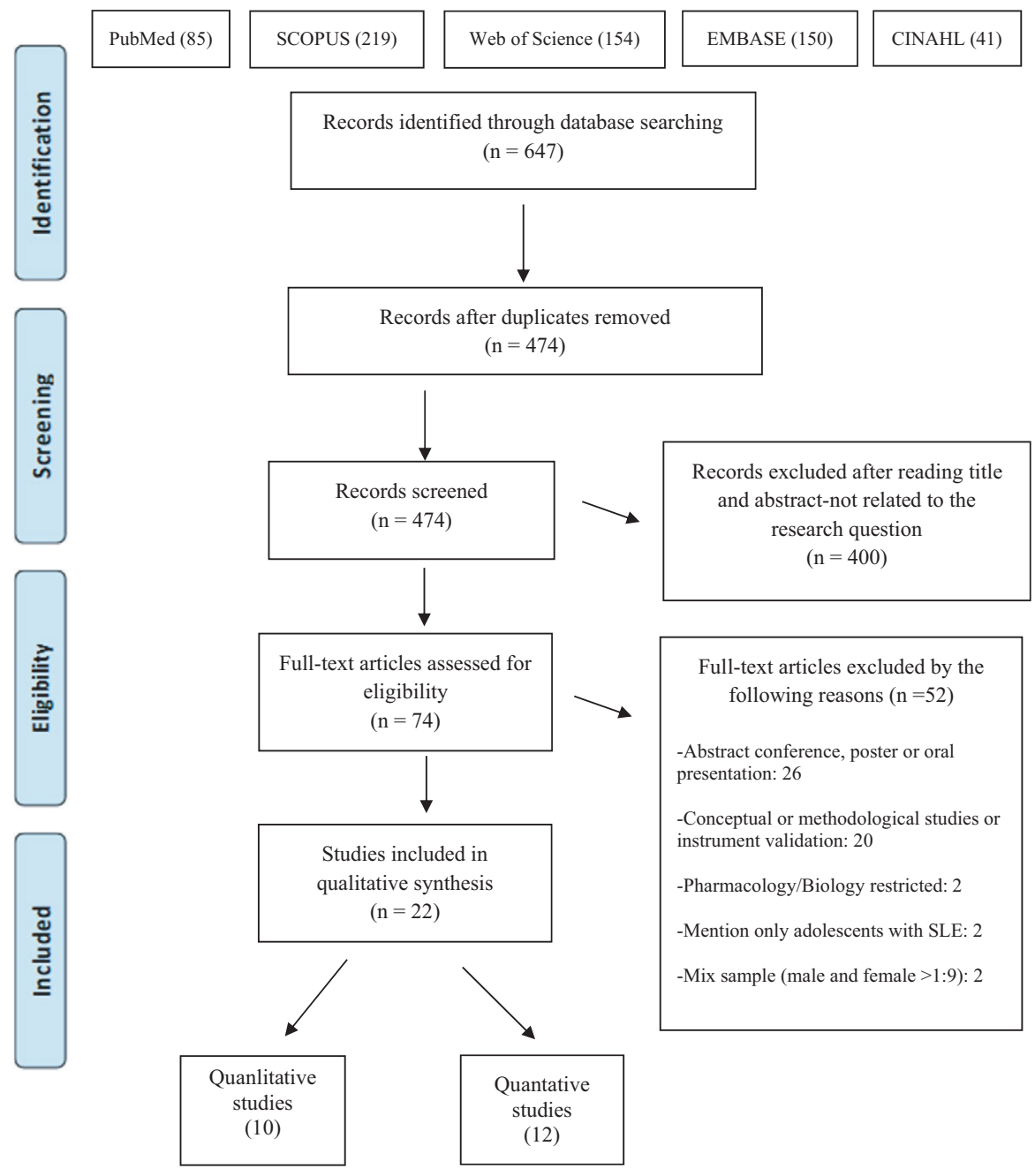




\section{3 | RESULTS}

\section{1 | Search results}

Of the 647 articles identified, 173 were removed as duplicates. The inclusion and exclusion process included a peer review of the titles and abstracts of 474 articles, performed by 2 authors (LR and MSS), to identify studies that potentially met the inclusion criteria, followed by a full-text reading of 74 articles. Disagreements on the eligibility of articles were discussed with the third author (FGS) until consensus was reached. By consensus, 22 articles were finally selected for analysis. The flow chart in Figure 1 shows the studies included in the main analysis.

\section{2 | Description of studies}

Of the 22 studies, 15 were cross-sectional. Twelve studies had a quantitative approach, and 1 of them had a quasi-experimental design. The remaining 10 had a qualitative design. Figure 2 presents the main topics of the articles. These topics were always related to $\mathrm{Bl}$, either as a domain or as a question in a questionnaire or as an emerging theme in comments made by study participants. The results are for a total of 3394 participants. A large variation in sample size was observed, ranging between 6 and 1259 participants.

For the quantitative studies, the alpha coefficients of the applied instruments were .96 for the Body Image QoL Inventory (BIQLI), ${ }^{22}$ .91 for the depression subscale of the Systemic Lupus Erythematosus Needs Questionnaire (SLENQ), ${ }^{23,24} .73$ for an adapted version of the
Body Image Questionnaire, ${ }^{10}$ and .93 for the Pain \& Vitality domain and .94 for the BI domain of the LupusPRO questionnaire. ${ }^{25}$ In studies that did not calculate Cronbach's alpha, evaluations from previous studies were reported. ${ }^{26-30}$

Quantitative studies carried out bivariate analyses using the following statistical tests: (a) Chi-squared test; $;^{24,27-29,31}$ (b) Student's $t$ test; ${ }^{10,26,30,31}$ (c) one-way analysis of variance (ANOVA); ${ }^{23,24}$ (d) Mann-Whitney $U$ test; ${ }^{27,28}$ and (e) correlations. ${ }^{28,30}$ When indicated, non-parametric tests were applied. ${ }^{28,29,31,32}$ Some studies also performed multivariate analyses. ${ }^{10,24-27,30}$

Qualitative studies examining the singularity of living experiences, the emerging cascading process, and the revelations of the participants $^{33}$ included 4 phenomenological studies, ${ }^{11,34-36} 3$ conceptual analysis studies based on focus groups, ${ }^{37-39}$ and a content analysis of individual discourse in 3 studies. ${ }^{40-42}$ The data interpretation process was supported by Dedoose software ${ }^{43}$ in 1 case $^{38}$ and NVIVO software ${ }^{44}$ in 2 cases, ${ }^{40,42}$ whereas 7 cases did not clarify whether data were analyzed manually or with software.

Table 1 presents a summary of the structures of the 22 selected articles.

\section{3 | Critical appraisal}

In addition to the thematic analysis, articles were evaluated for methodological quality and the risk of bias separately by 2 authors (Figure 3). All studies met more than $70 \%$ of the criteria for methodological quality, which ranged between moderate and high. In the case of the level of evidence, $50 \%$ of the studies were at level $4 \mathrm{~b}$, $45.5 \%$ at level 3 , and $4.5 \%$ at level $2 \mathrm{c}$.

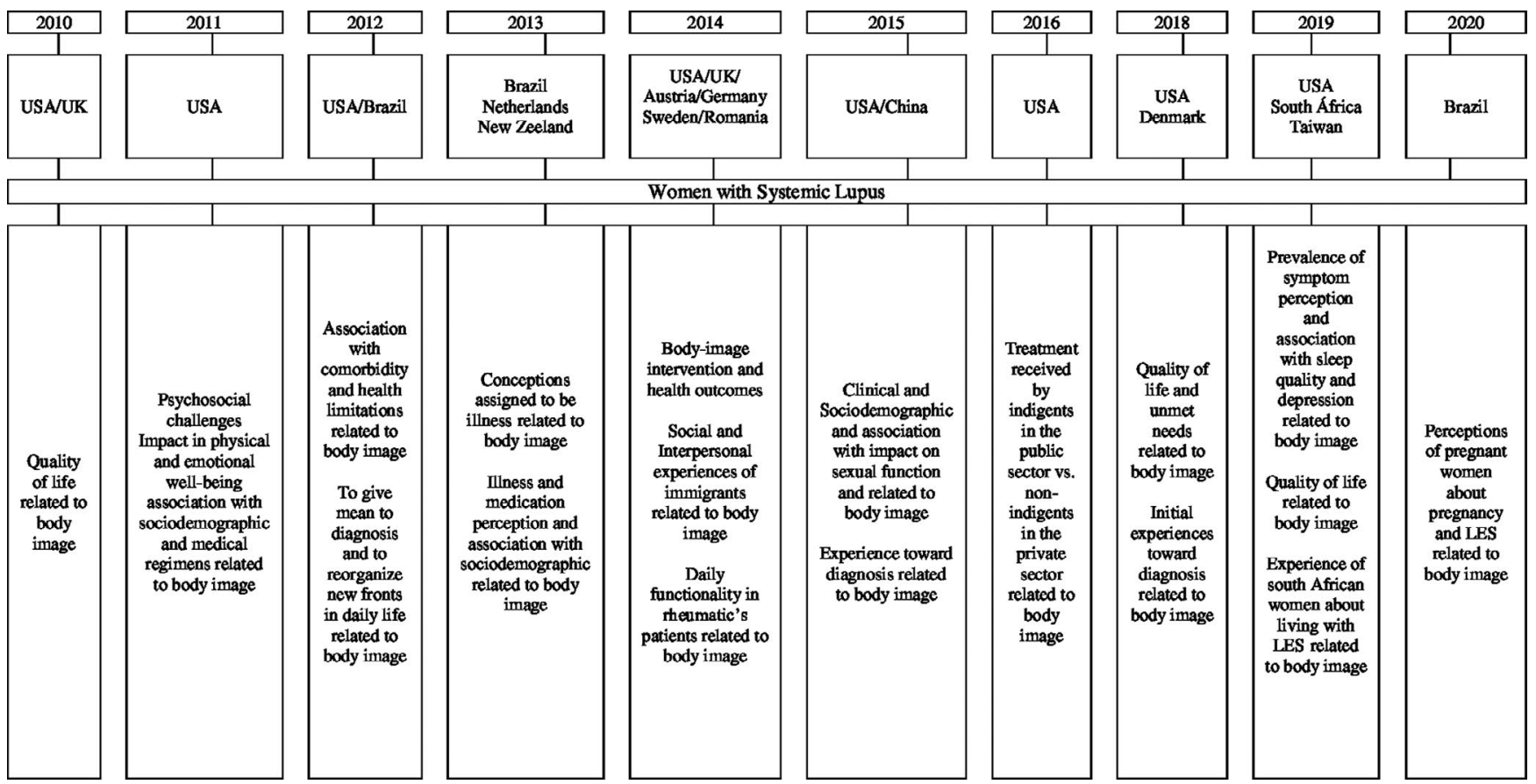

FIGURE 2 Publication in the last 10 years on various topics related to body image in the discussion of article 


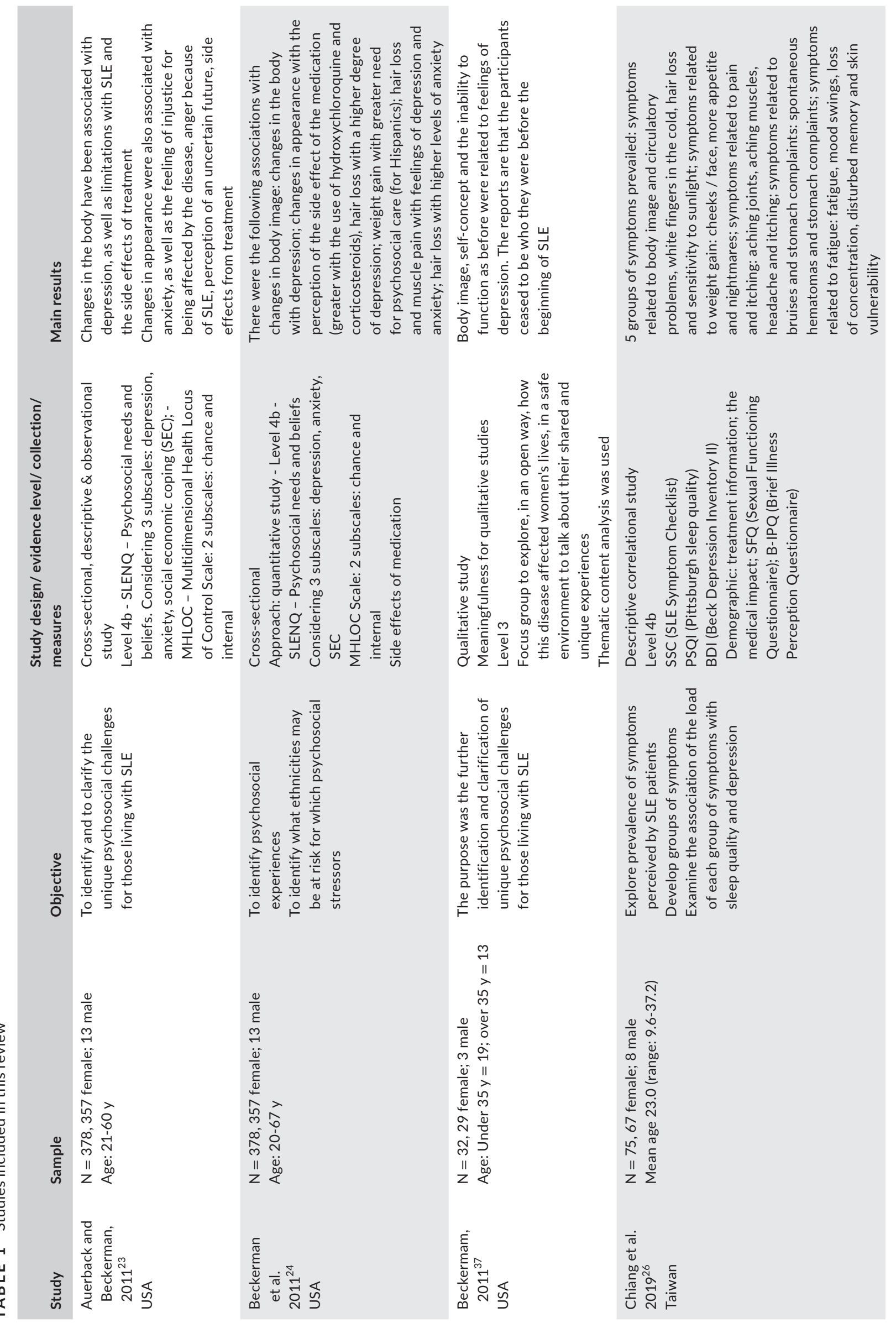




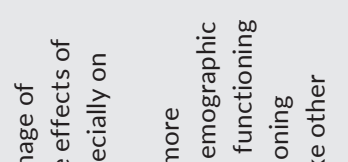
E.

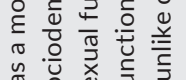
留

ते

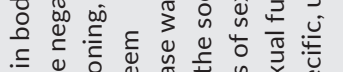

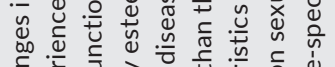

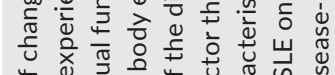

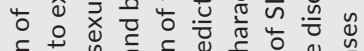

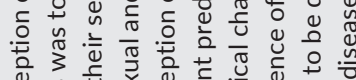

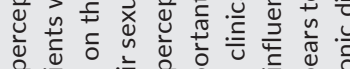

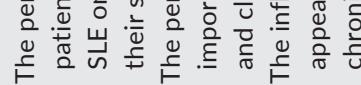

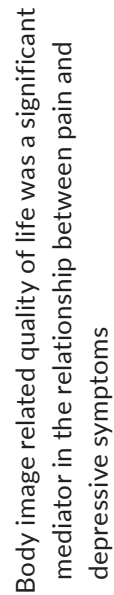

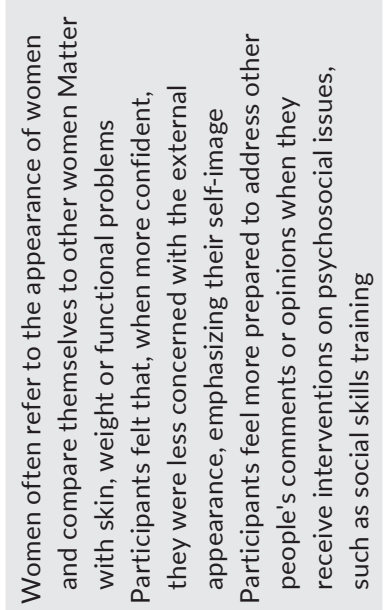

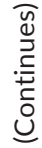

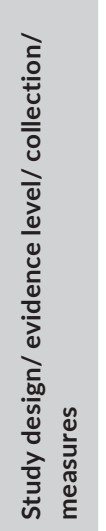

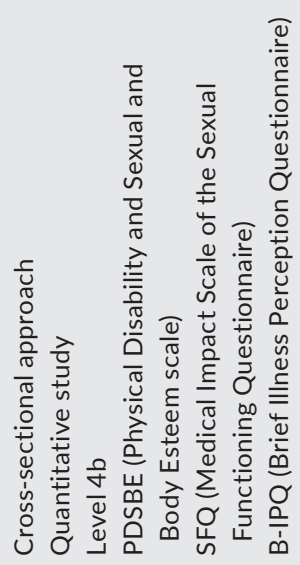
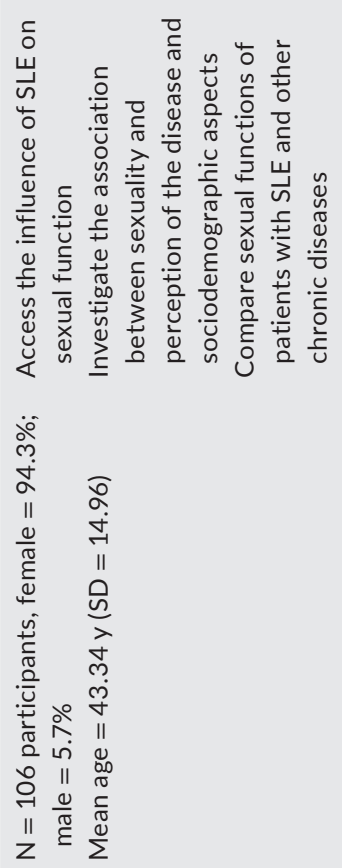

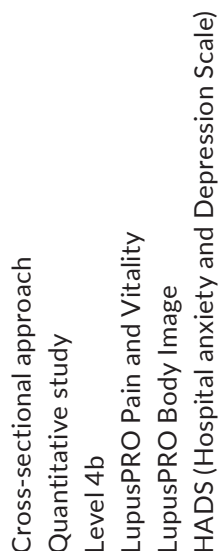

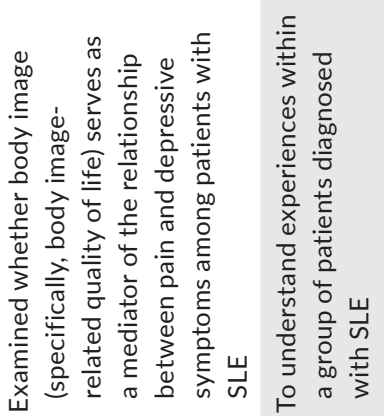

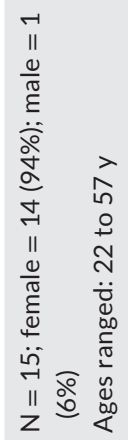

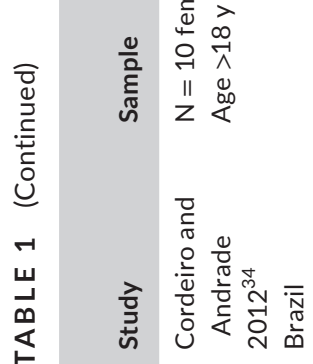

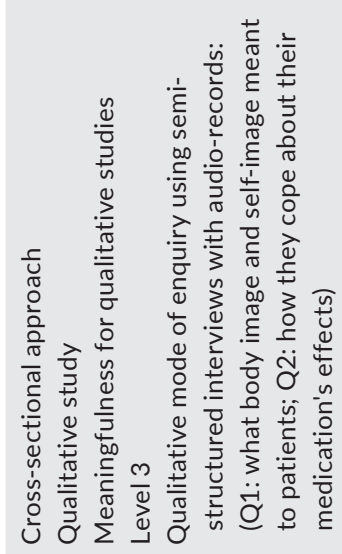

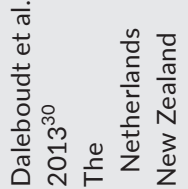

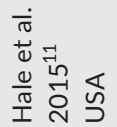



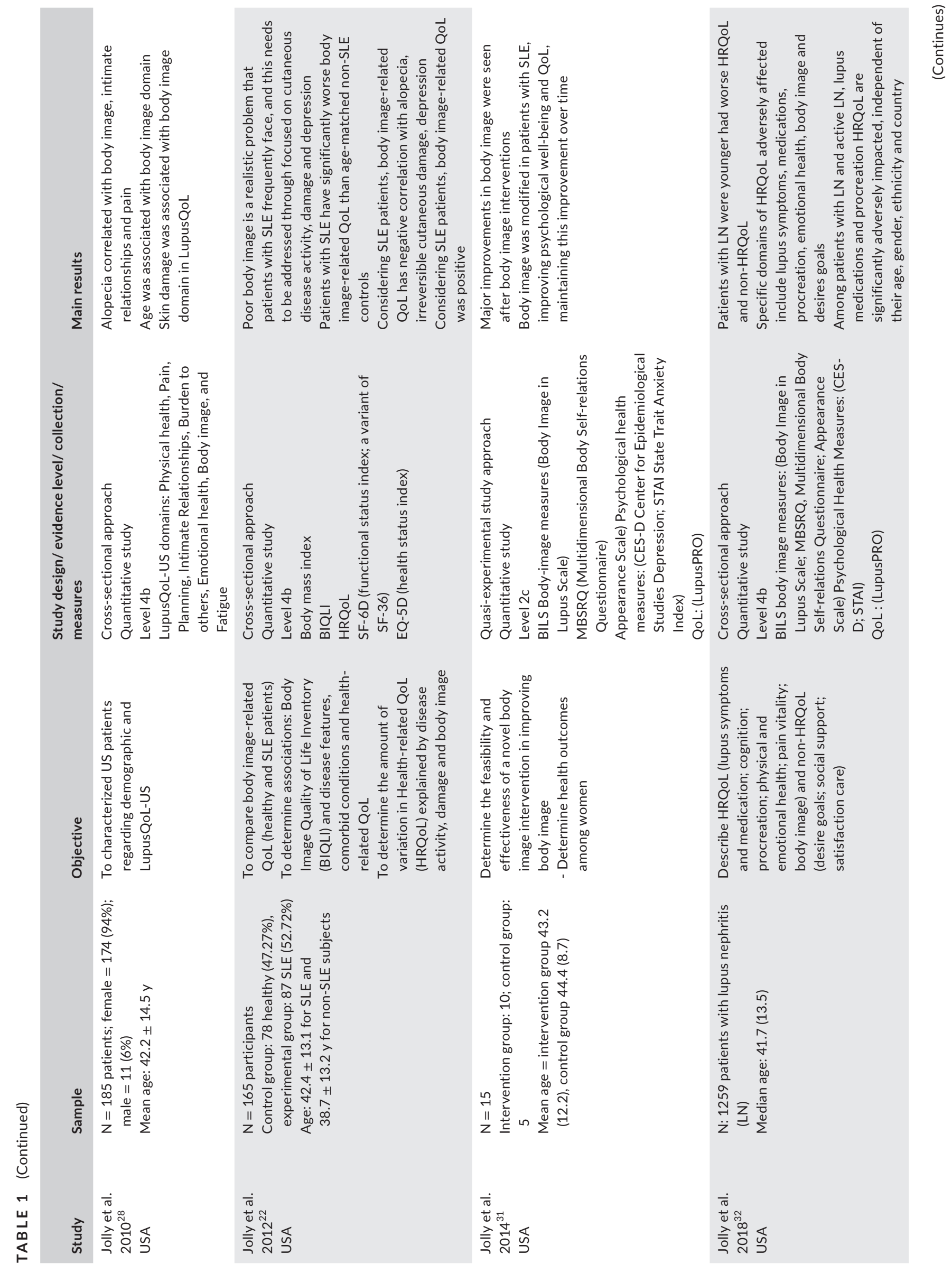

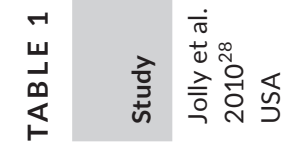

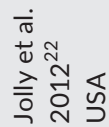
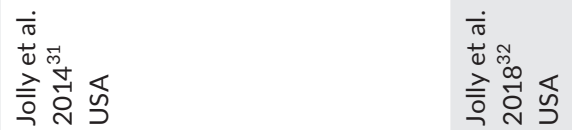

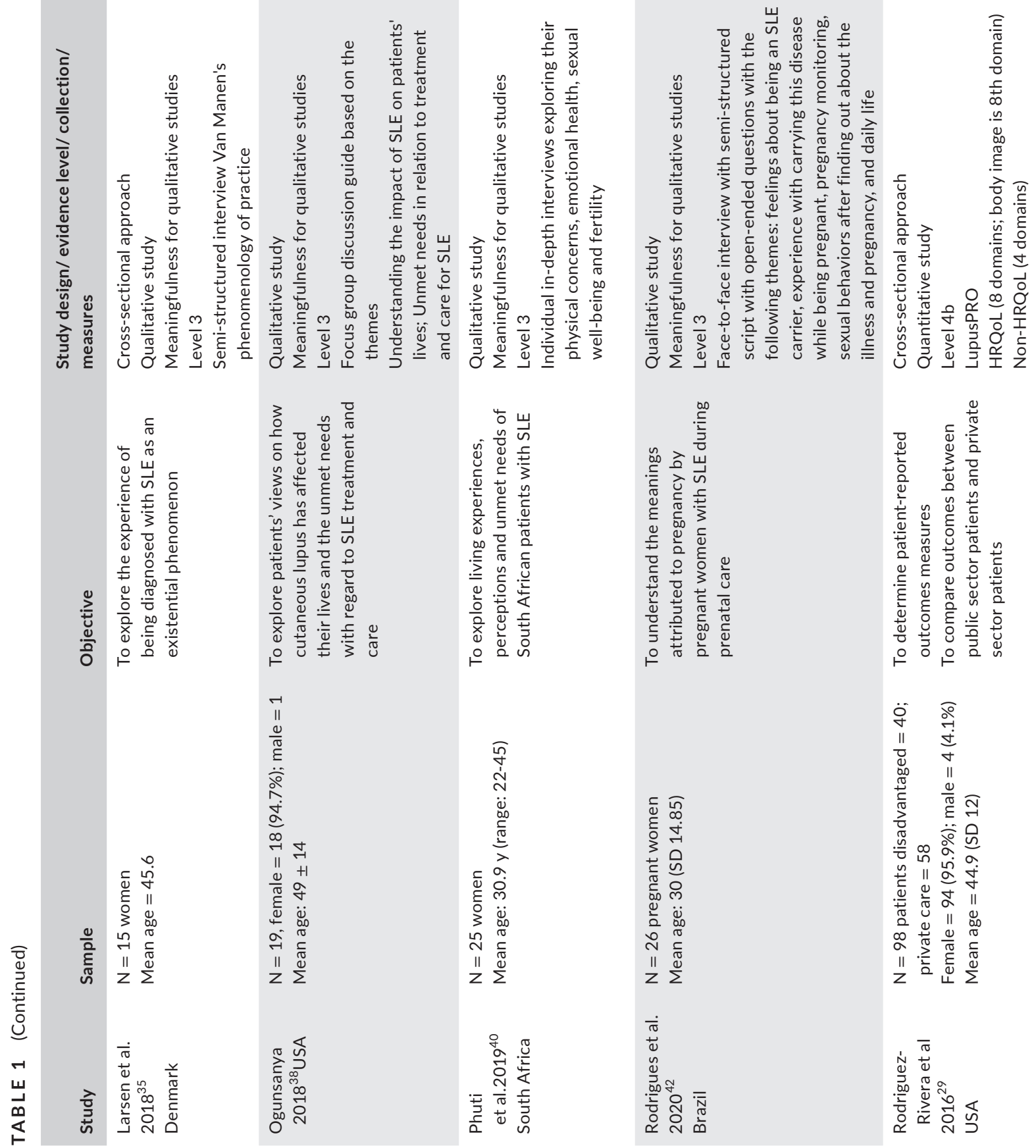

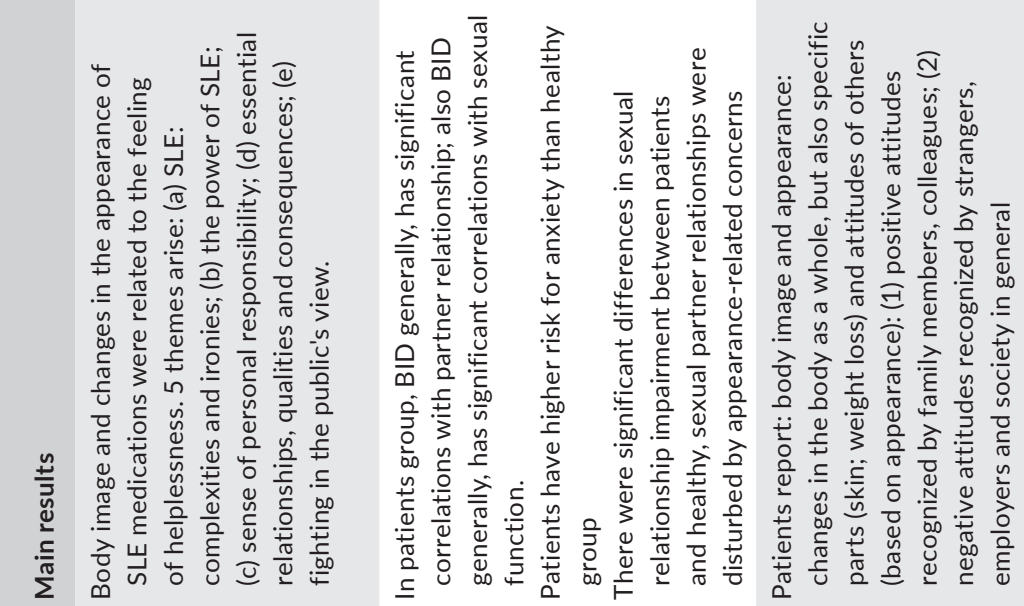

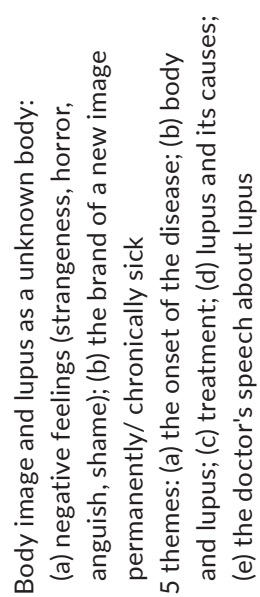
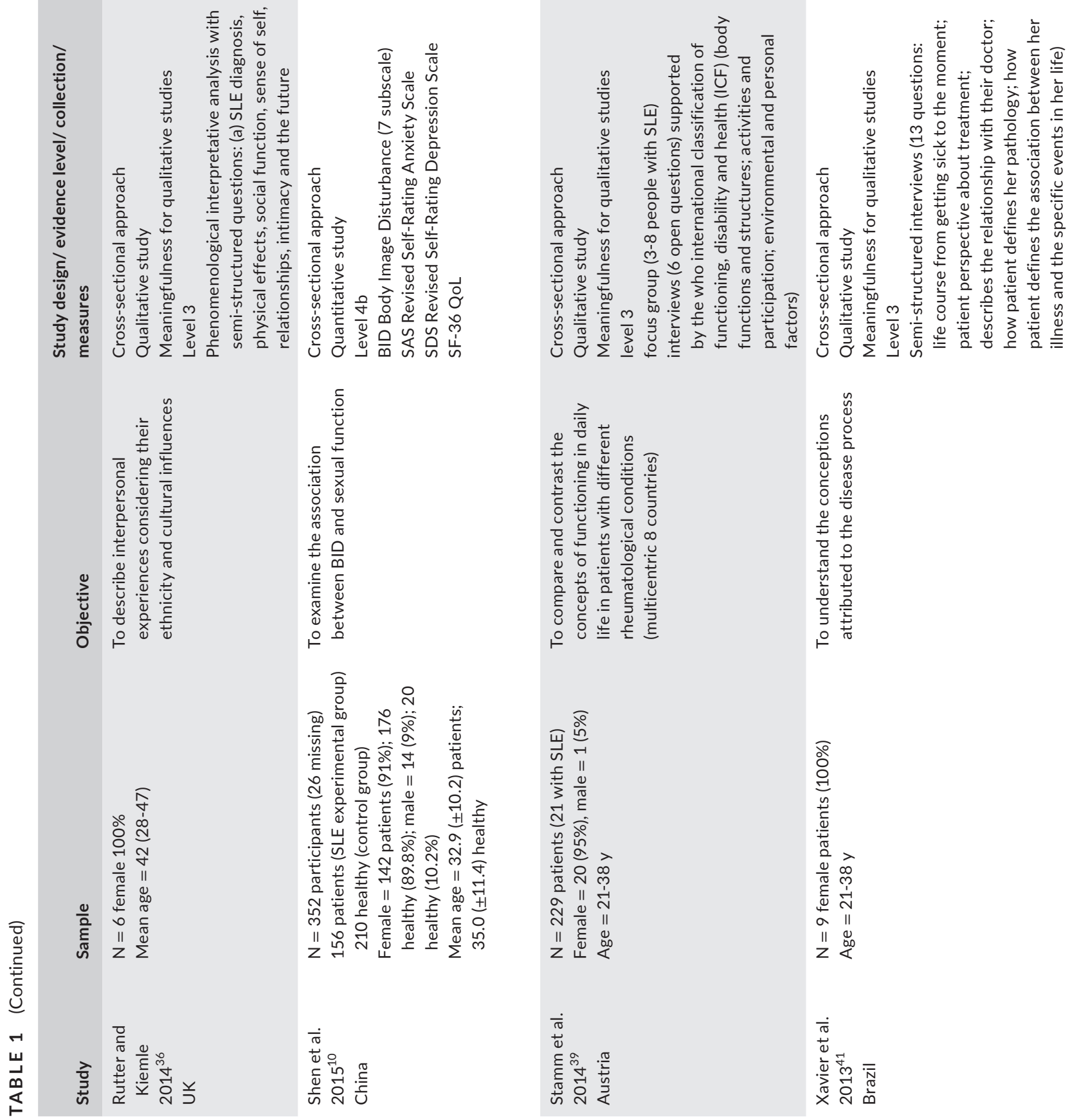

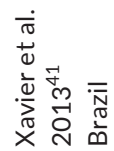




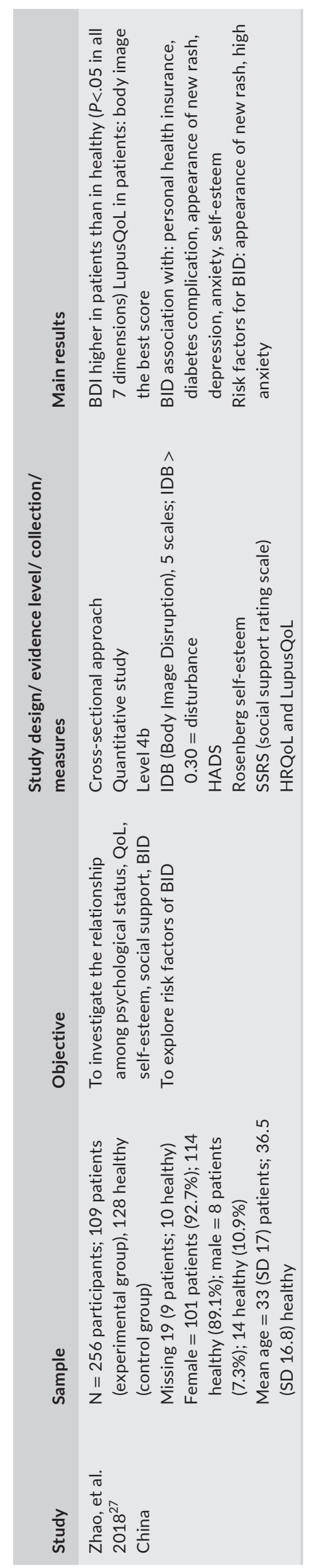

\section{4 | Thematic categories}

Three thematic categories were created from the themes that emerged from the data to organize and present the metaaggregation ${ }^{20,21}$ performed during the analysis of the articles: (1) depression and anxiety associates with body changes (hair loss, weight gain); (2) BI reflecting the disease; and (3) confrontations and interventions to promote acceptance and adaptation to the new image.

Within each category, the results of the qualitative and quantitative studies are presented separately for didactic purposes. However, the complementarity of these studies is emphasized in the answer to the question that guides this review. Figure 4 shows the clustering of the studies.

\subsection{1 | Depression and anxiety associates with body changes (hair loss, weight gain)}

The disease causes body changes and the medications used to treat it cause significant discomfort.

\section{BI, self-concept, and the use of SLE medications}

SLE is commonly associated with hair loss and changes in appearance, ${ }^{23,40}$ as well as psychosocial needs ${ }^{37}$ and symptoms related to vasoconstriction. ${ }^{26}$ Emotional and sexual life is disturbed, ${ }^{10,29}$ and QoL suffers as a result of the disease. ${ }^{22,24}$ In addition, problems with facial appearance and weight have a strong correlation with BI. 27,40

QoL related to $\mathrm{BI}$ mediates the relationship between pain and depressive symptoms. ${ }^{25}$

Medications sometimes made participants feel worse than before treatment, and the discontinuation of treatment or non-adherence to medication due to side effects was not uncommon. ${ }^{11}$

The process of changes in BI brought about by SLE involves uncertainties, losses, and pain and is permeated by anguish. ${ }^{41}$

\section{Visibility of disease and the judgment of others}

Gender identity is often influenced by BI. Once an SLE patient compares themselves to stereotypes, ${ }^{11}$ they experience a sense of lost identity ${ }^{35}$ and withdraw from social interaction. A sense of having no autonomy in deciding how to get better may also emerge, and the patient may submit themself to their sick body. ${ }^{36}$ Furthermore, body shame and low self-esteem can increase feelings of self-destruction. ${ }^{27,35}$

SLE patients felt they did not recognize themselves when looking in the mirror because they felt that the skin and hair damage altered their appearance, making the disease visible, and, therefore, making the situation more serious. ${ }^{34}$ There is dissatisfaction related to $\mathrm{BI}$ due to the visibility of skin changes, such as scars, alopecia and depigmentation and weight gain (due to the use of steroids). ${ }^{38}$ 


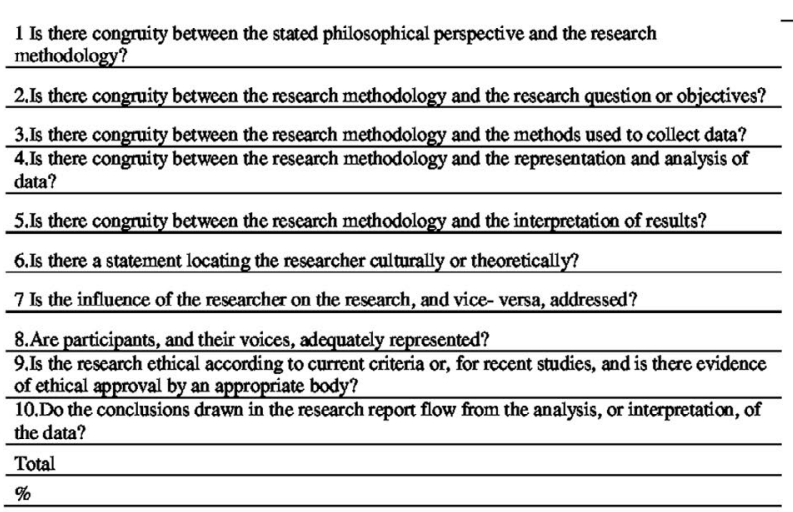

\begin{tabular}{|c|c|c|c|c|c|c|c|c|c|}
\hline $\begin{array}{c}\text { Beckerman } \\
2011\end{array}$ & $\begin{array}{c}\text { Cordeiro } \\
2013 \\
\end{array}$ & $\begin{array}{l}\text { Hale } \\
2015 \\
\end{array}$ & $\begin{array}{c}\text { Larsen } \\
2018 \\
\end{array}$ & $\begin{array}{c}\text { Ogunsanya } \\
2018\end{array}$ & $\begin{array}{l}\text { Puthi } \\
2019\end{array}$ & $\begin{array}{c}\text { Rodrigues } \\
2020\end{array}$ & $\begin{array}{c}\text { Rutter } \\
2015\end{array}$ & $\begin{array}{l}\text { Stam } \\
2014 \\
\end{array}$ & $\begin{array}{c}\text { Xavier } \\
2013 \\
\end{array}$ \\
\hline 0 & 0 & 0 & 0 & 0 & 0 & 0 & 0 & 0 & 0 \\
\hline - & 0 & 0 & 0 & 0 & 0 & 0 & 0 & 0 & 0 \\
\hline 0 & 8 & 0 & 0 & 0 & 0 & 0 & 0 & 8 & 0 \\
\hline 0 & 0 & 0 & 0 & 0 & 0 & 0 & 0 & 0 & 0 \\
\hline 0 & 0 & 0 & 0 & 0 & 0 & 0 & 0 & 0 & 0 \\
\hline 0 & O & 0 & 0 & 0 & 0 & 0 & 0 & P & 0 \\
\hline 0 & ( & 0 & 0 & 0 & 0 & 0 & 0 & 0 & 0 \\
\hline 0 & 0 & 0 & 0 & 0 & 0 & 0 & 0 & - & 0 \\
\hline 0 & 0 & 0 & 0 & 0 & 0 & 0 & 0 & 0 & 0 \\
\hline 0 & 0 & 0 & 0 & 0 & 0 & 0 & 0 & 0 & 0 \\
\hline $9 / 10$ & $8 / 10$ & $9 / 10$ & $10 / 10$ & $10 / 10$ & $10 / 10$ & $10 / 10$ & $9 / 10$ & $9 / 10$ & $8 / 10$ \\
\hline 90 & 80 & 90 & 100 & 100 & 100 & 100 & 90 & 90 & 80 \\
\hline
\end{tabular}

Qualitative Critical Appraisal

\begin{tabular}{|c|c|c|c|c|c|c|c|c|c|c|c|}
\hline & $\begin{array}{c}\text { Auerbach } \\
2011\end{array}$ & $\begin{array}{l}\text { Beckerman } \\
2011\end{array}$ & $\begin{array}{l}\text { Chiang } \\
2019\end{array}$ & $\begin{array}{c}\text { Daleboudt } \\
2013\end{array}$ & $\begin{array}{c}\text { Gholizade } \\
2019\end{array}$ & $\begin{array}{l}\text { Jolly } \\
2010\end{array}$ & $\begin{array}{l}\text { Jolly } \\
2012\end{array}$ & $\begin{array}{l}\text { Jolly } \\
2018\end{array}$ & $\begin{array}{c}\text { Rodriguez-Rivera } \\
2016\end{array}$ & $\begin{array}{l}\text { Shen } \\
2015\end{array}$ & $\begin{array}{l}\text { Zhao } \\
2018\end{array}$ \\
\hline 1.Inclusion criteria are defined & O & O & O & O & O & O & O & O & 0 & O & O \\
\hline 2.Subjects and context detailled & 0 & - & O & O & - & - & - & O & O & - & 0 \\
\hline 3. Exposition measured in a valid and reliable way & 0 & O & O & O & - & - & - & O & O & - & - \\
\hline 4. Objective and standardized criteria used & 0 & - & 0 & 0 & O & - & 0 & O & O & 0 & O \\
\hline 5. Confounding factors identified & O & O & - & - & - & - & 0 & O & O & - & - \\
\hline 6. Strategies declared to deal with confounding factors & $\mathbf{0}$ & - & O & O & O & - & O & - & 0 & - & - \\
\hline 7. Results evaluated in a valid and reliable way & O & O & O & ○ & O & - & O & O & O & O & O \\
\hline 8. Appropriate statistics texts & - & O & O & O & O & O & O & O & O & ○ & ○ \\
\hline Total & $5 / 7$ & $7 / 8$ & $6 / 7$ & $8 / 8$ & $6 / 7$ & $5 / 7$ & $8 / 8$ & $7 / 8$ & $6 / 7$ & $8 / 8$ & $7 / 8$ \\
\hline$\%$ & 71,4 & 87.5 & 85,7 & 100 & 85,7 & 71,4 & 100 & 87.5 & 85,7 & 100 & 87.5 \\
\hline
\end{tabular}

\section{Cross-sectional Critical A praisal}

\begin{tabular}{lc} 
1. Is it clear "cause" and "effect" & Jolly \\
\hline 2. Participants were in some similar comparison & \\
\hline 3.Participants had the same treatment & \\
\hline 4.Control group exists & \\
\hline 5. Exists multiple measurements before/after intervention & \\
\hline 6. Follow-up / complete OR differences described and analyzed & \\
\hline 7. Results included in any comparison measured in the same way & \\
\hline 8. Results measured reliably & \\
\hline 9.Appropriate statistics texts & \\
\hline Total &
\end{tabular}

-NA - No Yes Unclear

FIGURE 3 Quality appraisal of the included studies

\subsection{2 $\mathrm{BI}$ reflecting the disease}

Appearance does not reflect who people with lupus nephritis are. ${ }^{29,31}$ Ethnicity and other individual factors have an impact on the prevalence and severity of the disease, and may generate different feelings about $\mathrm{BI}$ in each person. ${ }^{32}$ Many people with SLE use cosmetics to help their self-image, ${ }^{31}$ a time-consuming and expensive process. $^{29}$

Pain and swelling in the joints are common for these people, making them unable to participate in activities, which causes insecurity by altering their self-concept. ${ }^{35}$ Pregnant women in the third trimester feel strange in their own bodies, often experiencing social isolation, sadness, and hopelessness related to this perception of their BI. ${ }^{42}$ People expressed a desire to have the body they had before the onset of lupus symptoms. ${ }^{38}$

\subsubsection{Confrontations and interventions to promote acceptance of and adaptation to the new BI}

Women with SLE experience major BID; 2 authors explore the relationship between the existence of lupus and BID, ${ }^{10,27}$ and another highlights that women with SLE have a BI related with age but not with time of disease. ${ }^{28}$ Confrontation with the new $\mathrm{BI}$ appears 


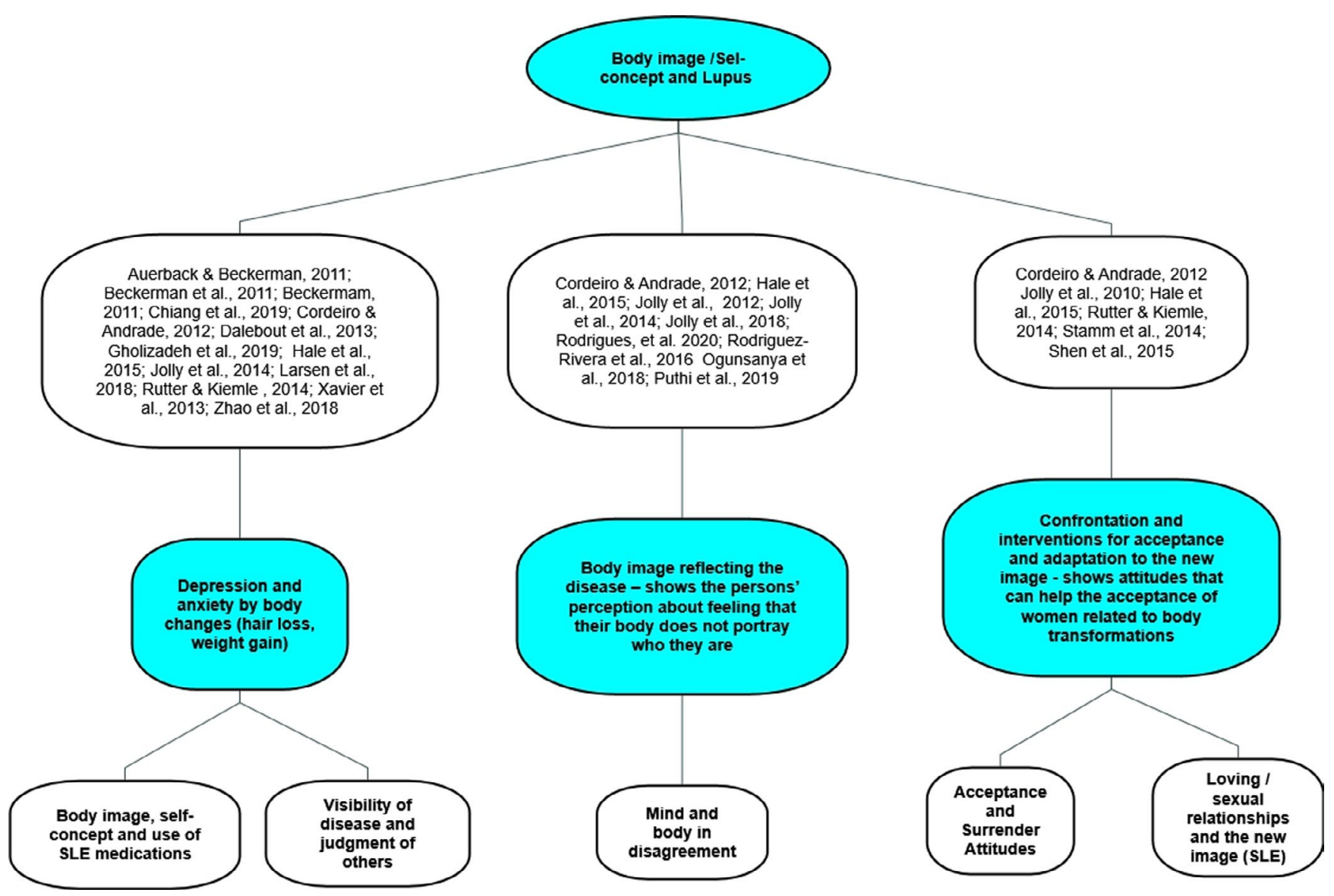

FIGURE 4 Clustering of included studies

to be relevant for the majority of SLE patients, and many change their lifestyles and attitudes to adapt to the disease and to their changing body. ${ }^{32}$

\subsubsection{Attitudes of acceptance and surrender}

Acceptance of the disease, expressed as surrendered attitudes, suggests an internal lived experience. ${ }^{35}$ Forms of communication such as irony, to better face the disease and remain unhurt, are common.. ${ }^{36}$ Better acceptance of oneself can be achieved by integrating into patient groups. ${ }^{39}$

\subsection{5 | Loving/sexual relationships and acceptance of the changed body}

Appearance-related concerns and sexual problems are associated ${ }^{10}$ with SLE patients. Age, marital status, and BID are predictors of impairments between SLE patients and their partners, whereas BID scores and education are more closely associated with impairments in patients' sexual functioning. ${ }^{10}$

Unattractiveness is a major feeling reported by women with SLE, compared to those with other chronic diseases. ${ }^{30}$ However, their emotions and feeling of coherence could explain the participants' perception of attractiveness. ${ }^{30}$ Impaired sexual function, related to distress and deficiencies in the patient's social life, suggests a link between physical function and psychological function, which can contribute to sexual health and overall QoL. ${ }^{10}$

The female role in marriage intimacy, pertinent to most women, is often not fulfilled once $\mathrm{BI}$ issues are exacerbated. ${ }^{36} \mathrm{~A}$ restricted life and the loss of experiences and relationships bring feelings of helplessness and small horizons. ${ }^{36}$ These disease limitations significantly affect relationships. ${ }^{10}$

\section{4 | DISCUSSION}

\section{1 | Considerations of study design and population representativeness}

The results of this review are representative in terms of the SLE population. The 3394 participants in the studies came from 5 continents: Asia (Taiwan and China), Africa (South Africa), North and South America (USA and Brazil), Europe (Denmark, UK, Austria, Netherlands), and Oceania (New Zealand). Given the assessment of such a diverse population, it makes sense that $\mathrm{BI}$, a burning problem among people with lupus, should be explored in different cultures. 


\section{2 | Considerations of measures of self-image}

All instruments used in the studies included in this review are validated and widely used in research. However, we emphasize that while some instruments focused on $\mathrm{BI},{ }^{10,22,27,31,32}$ others did not. Instead, they concentrated on issues such as QoL, ${ }^{18,25,27-29}$ psychosocial needs, ${ }^{23,24}$ quality of sleep, and sexual disfunction, ${ }^{26,30}$ but used $\mathrm{BI}$ as a questionnaire domain to measure these factors; therefore, they provide information on BI for discussion, even if indirectly.

\subsection{Synthesis of research findings}

Focusing on the changes and adaptations that occur in the $\mathrm{BI}$ of people with SLE (primary interest) and on their self-concept (secondary interest) (considering: [a] the perceptions that patients have of their bodily changes; [b] how patients deal with changes in their bodies; and (c) what are their perceptions of bodily changes), 3 thematic categories that were elaborated from the themes emerged from the data: (a) depression and anxiety caused by bodily changes (hair loss and weight gain); (b) BI reflecting the SLE, demonstrating the person's perception that their body does not portray who they are; and (c) coping and interventions for acceptance and adaptation to the new $\mathrm{BI}$, indicating attitudes that can facilitate women's acceptance of bodily transformations.

The most reported and evaluated feelings associated with $\mathrm{BI}$ changes were depression, ${ }^{22-27}$ anxiety, ${ }^{10,23,24,27}$ social isolation, ${ }^{42}$ anguish, ${ }^{41}$ and helplessness. ${ }^{36}$ These feelings can lead to illness if adequate support is not provided for coping with them, leading to aggravation of the condition of the person with SLE. ${ }^{45}$ In addition, a feeling of loss and a lack of functionality related to the chronicity of the disease were reported. ${ }^{39}$

The condition of individuals with lupus is like that of chronic patients, and the limitations imposed can cause suffering, anguish, uncertainty, loss, and pain. ${ }^{41}$ Despite having the same disease, with the same symptoms and even the same treatments (medication and dosage), each patient's experience of SLE is unique; ${ }^{41}$ therefore, $\mathrm{BI}$ and self-concept can be altered by the conditions imposed by the disease, which may have an impact on sexual behavior ${ }^{27}$ and personal relationships. ${ }^{11}$

Having and maintaining a positive attitude under disease conditions can be an actively difficult pursuit, and individuals with SLE must preserve their self-image despite the changes caused by the disease. Therefore, people with lupus report the use of "symbolic masks" to hide, such as keeping a smile on their face or appearing to be strong and cheerful, to meet the expectations of others, even if they are experiencing deep sadness ${ }^{11}$ as a result of loss of identity, ${ }^{34}$ which must be reconstructed.

People with lupus report a lack of support for the psychosocial aspects of the disease. ${ }^{11}$ In the case of physical aspects, they feel that their bodies are no longer reliable compared to when they were healthy; thus, normal functioning becomes strange and activities of everyday life require great effort. ${ }^{34}$

\subsection{Limitations of primary studies}

Although SLE most often affects women, some studies used mixed samples. Therefore, we chose to exclude studies that did not reflect the gender proportion indicated in the literature, which is 1 man to every 9 women with SLE. ${ }^{12}$ From a gender perspective, studies should be designed to include only women or only men. However, we ensured that the studies considered in the review predominantly included female subjects; therefore, the themes identified here reflect the responses of women to $\mathrm{BI}$ and self-concept. The heterogeneity of the studies did not permit a deeper comparative analysis.

\subsection{Strengths of the systematic review}

The present study provides a comprehensive explanation of the phenomena related to $\mathrm{BI}$ in SLE. As the participants of the selected studies were women, our review brings a gender perspective that may be different, given society's stereotypes of female BI.

\section{6 | Implications for research}

We argue that the effects of the psychosocial issues related to $\mathrm{BI}$ are essential considerations for health professionals when treating people with SLE.

Ongoing research examining the association of depression and anxiety with BID and SLE and potential associations with other mental disorders remains important.

The use of extensive questionnaires, which can identify different aspects of $\mathrm{BI}$ in people with SLE, and the addressing of cultural differences, nuances, and the meanings of each concept are also suggested. We recognize that there are limitations on the description of strategies or interventions that help to adapt to changes in $\mathrm{BI}$ of people with lupus; this is an important issue to focus on in research.

\section{7 | Implications for clinical practice}

The starting point for clinical practice is the consideration by health professionals of the effects of the disease and treatment on the external appearance of patients and recognition of the associations of $\mathrm{BI}$ with anxiety and depression. Likewise, professionals need to value the difficulties and psychosocial pressures faced by people with SLE that have an impact on the process of coping with the disease and changes in $\mathrm{BI}$ and self-concept. Professionals must value how existential experiences can result in a paradoxical and turbulent period after the individual is diagnosed with SLE. Orientation activities are the initial strategy to deal with this issue.

Knowledge and presentation of therapeutic options can prevent or limit adverse effects and ameliorate the negative impacts of BI on QoL. These options include: (a) the use of sunscreen; (b) early referral, screening, and treatment of active disease, thereby 
limiting organ involvement and preventing impairment; ${ }^{21,28}$ (c) training in the use of suitable cosmetics; ${ }^{31}$ (d) early diagnosis, referral, and treatment of depression; ${ }^{22,23,25}$ and (e) coping and selfesteem exercises. ${ }^{31,34}$

\section{8 | Recommendations}

We summarize 3 main recommendations for health professionals: (a) the need to value the importance of changes in $\mathrm{BI}$ and the self-concept of people with lupus, in the same way that their experience of pain and physical limitations is valued, since the literature exposes the impact of these changes; (b) the need to consider psychosocial problems and early screening for symptoms of illnesses due to depression, anxiety and relationship problems (eg, social isolation and helplessness) as the literature shows that they are associated with $\mathrm{Bl}$; and (c) the need to offer products, such as cosmetics, that can assist in coping with BI changes, since good results have been shown in a pilot study.

\section{5 | CONCLUSION}

Based on references available in databases, we believe to the best of our knowledge that our study is the first systematic review of $\mathrm{BI}$ and self-concept in people suffering from SLE. The most common changes reported were weight gain and changes in skin, hair, and joints, which impacted $\mathrm{BI}$ and functionality. The most reported feelings related to these changes were depression, anxiety, social isolation, helplessness, and anguish. Feelings of loss and lack of functionality were also related to the chronicity of the disease.

This study highlights the crucial importance of the dimensions of self-concept and $\mathrm{BI}$ for assessing QoL of individuals with lupus. These aspects can reveal the patient's relationship with SLE and how it can impact his/her life, particularly if these issues are not actively addressed by health professionals.

\section{ACKNOWLEDGEMENTS}

Providing validation of search: SARHAS'Lab, UEVORA. Providing language help: Cambridge Proofreading.

\section{CONFLICT OF INTEREST}

None declared.

\section{ETHICS APPROVAL}

Formal ethicS approwval is not required for this type of study.

\section{STATEMENT REGARDING INFORMED CONSENT}

Formal consent is not required for this type of study.

\section{ORCID}

Larissa Rodrigues (iD https://orcid.org/0000-0001-8714-7010

Maria M. F. Sim-Sim (D) https://orcid.org/0000-0002-0028-2664

Luis Sousa iD https://orcid.org/0000-0002-9708-5690
Débora B. Faria-Schützer (iD https://orcid.org/0000-0001-7918-6714 Fernanda G. Surita (iD https://orcid.org/0000-0003-4335-0337

\section{REFERENCES}

1. Grogan S. Body image: Understanding body dissatisfaction in men, women and children. In: Grogan S, ed. Body image: Understanding body dissatisfaction in men, women and children, 3rd edn. New York: Routledge; 2017:250-xiv.

2. Jarry JL, Ip K. The effectiveness of stand-alone cognitivebehavioural therapy for body image: A meta-analysis. Body Image. 2005;2(4):317-331

3. Cash TF. Body image: past, present, and future. Body Image. 2004;1(1):1-5.

4. Tiggemann M. Sociocultural perspectives on human appearance and body image. Body image: A handbook of science, practice, and prevention, 2nd edn. New York: Guilford Press; 2011:12-19.

5. Watson B, Fuller-Tyszkiewicz M, Broadbent J, Skouteris H. The meaning of body image experiences during the perinatal period: A systematic review of the qualitative literature. Body Image. 2015;14:102-113.

6. Fuller-Tyszkiewicz M, Skouteris H, Watson BE, Hill B. Body dissatisfaction during pregnancy: a systematic review of cross-sectional and prospective correlates. J Health Psychol. 2013;18(11):1411-1421.

7. Davison TE, McCabe MP. Adolescent body image and psychosocial functioning. J Soc Psychol. 2006;146(1):15-30.

8. Dyer A, Borgmann E, Feldmann RE, et al. Body image disturbance in patients with borderline personality disorder: Impact of eating disorders and perceived childhood sexual abuse. Body Image. 2013;10(2):220-225.

9. Partridge KA, Robertson N. Body-image disturbance in adult dialysis patients. Disabil Rehabil. 2011;33(6):504-510.

10. Shen $\mathrm{B}, \mathrm{He} \mathrm{Y}$, Chen $\mathrm{H}$, et al. Body image disturbances have impact on the sexual problems in Chinese systemic lupus erythematosus patients. J Immunol Res. 2015;2015: 204513.

11. Hale ED, Radvanski DC, Hassett AL. The man-in-the-moon face: a qualitative study of body image, self-image and medication use in systemic lupus erythematosus. Rheumatology (Oxford). 2015;54(7):1220-1225.

12. Borella E, Lojacono A, Gatto M, et al. Predictors of maternal and fetal complications in SLE patients: a prospective study. Immunol Res. 2014;60(2-3):170-176.

13. Petri M, Orbai AM, Alarcón GS, et al. Derivation and validation of the Systemic Lupus International Collaborating Clinics classification criteria for systemic lupus erythematosus. Arthritis Rheum. 2012;64(8):2677-2686.

14. Pastore DEA, Costa ML, Parpinelli MA, Surita FG. A critical review on obstetric follow-up of women affected by systemic lupus erythematosus. Rev Bras Ginecol Obstet. 2018;40(04):209-24

15. La Paglia GMC, Leone MC, Lepri G, et al. One year in review 2017: systemic lupus erythematosus. Clin Exp Rheumatol. 2017;35(4):551-561.

16. Moher D, Liberati A, Tetzlaff J, Altman DG. Preferred reporting items for systematic reviews and meta-analyses: the PRISMA statement. PLoS Med. 2009;6(7):e1000097.

17. Aringer M, Costenbader K, Daikh D, et al. European League Against Rheumatism/American College of Rheumatology classification criteria for systemic lupus erythematosus. Ann Rheum Dis. 2019;78(9):1151.

18. Braun V, Clarke V. Using thematic analysis in psychology. Qual Res Psychol. 2006;3(2):77-101.

19. Jordan Z, Lockwood C, Munn Z, Aromataris E. Redeveloping the JBI model of evidence based healthcare. Int J Evid Based Healthc. 2018;16(4):227-241. 
20. Joanna Briggs Institute. Reviewers' Manual: Methodology for JBI Mixed Methods Systematic Reviews. [Internet]. Adelaide: JBI; 2014. Available from: http://joannabriggs.org/assets/docs/sumari/ ReviewersManual_Mixed-Methods-Review-Methods-2014-ch1. pdf

21. Cardoso V, Trevisan I, Cicolella DA, Waterkemper R. Systematic review of mixed methods: method of research for the incorporation of evidence in nursing. Texto Contexto Enferm [Internet]. 2019;28:e20170279.

22. Jolly M, Pickard AS, Mikolaitis RA, et al. Body image in patients with systemic lupus erythematosus. Int J Behav Med. 2012;19(2):157-164.

23. Auerbach C, Beckerman N. What social workers in health care should know about lupus: A structural equation model. Health Soc Work. 2011;36(4):269-278.

24. Beckerman NL, Auerbach C, Blanco I. Psychosocial dimensions of SLE: implications for the health care team. J Multidiscip Healthc. 2011:4:63-72.

25. Gholizadeh S, Azizoddin DR, Mills SD, et al. Body image mediates the impact of pain on depressive symptoms in patients with systemic lupus erythematosus. Lupus. 2019;28(9):1148-1153.

26. Chiang YC, Huang JL, Wang $\mathrm{CH}$, Lee HC, Lee MY, Hsiao YC. Symptom clustering in patients with childhood-onset systemic lupus erythematosus. J Adv Nurs. 2019;75(1):54-62.

27. Zhao Q, Chen $\mathrm{H}$, Yan $\mathrm{H}$, et al. The correlations of psychological status, quality of life, self-esteem, social support and body image disturbance in Chinese patients with Systemic Lupus Erythematosus. Psychol Health Med. 2018;23(7):779-787.

28. Jolly M, Pickard SA, Mikolaitis RA, Rodby RA, Sequeira W, Block JA. LupusQoL-US benchmarks for US patients with systemic lupus erythematosus. J Rheumatol. 2010;37(9):1828-1833.

29. Rodríguez-Rivera DV, Rodríguez-Navedo Y, Nieves-Plaza M, Vilá LM. Patient-reported outcome measures in a population of medically indigent patients with systemic lupus erythematosus in Puerto Rico. SAGE Open Med. 2016;4:2050312116670927.

30. Daleboudt GMN, Broadbent E, McQueen F, Kaptein AA. The impact of illness perceptions on sexual functioning in patients with systemic lupus erythematosus. J Psychosom Res. 2013;74(3):260-264.

31. Jolly M, Peters KF, Mikolaitis R, Evans-Raoul K, Block JA. Body image intervention to improve health outcomes in lupus: a pilot study. J Clin Rheumatol. 2014;20(8):403-410.

32. Jolly M, Toloza S, Goker B, et al. Disease-specific quality of life in patients with lupus nephritis. Lupus. 2018;27(2):257-264.

33. Grossoehme DH. Overview of qualitative research. J Health Care Chaplain. 2014;20(3):109-122.
34. Cordeiro SM, Andrade MBT. Ser mulher e ter lúpus [Being a female and having lupus] [Ser mujer y tener lúpus]. Revista Enfermagem UERJ; 2012;20(5): Número Especial 1. 2013 05/08/.

35. Larsen JL, Hall EOC, Jacobsen S, Birkelund R. Being in a standstillof-life: women's experience of being diagnosed with systemic lupus erythematosus: a hermeneutic-phenomenological study. Scand J Caring Sci. 2018;32(2):654-662.

36. Rutter SJ, Kiemle G. Exploring the social and interpersonal experiences of South Asian women with a diagnosis of Systemic Lupus Erythematosus. Psychol Health. 2015;30(3):318-335.

37. Beckerman NL. Living with lupus: a qualitative report. Soc Work Health Care. 2011;50(4):330-343.

38. Ogunsanya ME, Brown CM, Lin D, Imarhia F, Maxey C, Chong BF. Understanding the disease burden and unmet needs among patients with cutaneous lupus erythematosus: A qualitative study. Int J Womens Dermatol. 2018;4(3):152-158.

39. Stamm T, Hieblinger R, Boström C, et al. Similar problem in the activities of daily living but different experience: a qualitative analysis in six rheumatic conditions and eight European countries. Musculoskeletal Care. 2014;12(1):22-33.

40. Phuti A, Schneider M, Makan K, Tikly M, Hodkinson B. Living with systemic lupus erythematosus in South Africa: a bitter pill to swallow. Health Qual Life Outcomes. 2019;17(1):65.

41. Xavier HV, Zanotti SV, Ribeiro MAT. Concepções atribuídas por mulheres ao processo de adoecimento por Lúpus. Psicologia em Estudo. 2013;18:223-233.

42. Rodrigues L, Alves VLP, Sim-Sim MMF, Surita FG. Perceptions of women with systemic lupus erythematosus undergoing high-risk prenatal care: A qualitative study. Midwifery. 2020;87:102715.

43. Dedoose Version 8.0.35. Web Application for Managing, Analyzing, and Presenting Qualitative and Mixed Method Research Data. Los Angeles: Socio Cultural Research Consultants, LLC; 2018.

44. Edhlund BM. NVivo 10 essentials: your guide to the world's most powerful data analysis software. Stallarholmen, Sweden: Form \& Kunskap AB; 2012

45. Zhang L, Fu T, Yin R, Zhang Q, Shen B. Prevalence of depression and anxiety in systemic lupus erythematosus: a systematic review and meta-analysis. BMC Psychiatry. 2017;17(1):70.

How to cite this article: Rodrigues L, Sim-Sim MMF, Sousa L, Faria-Schützer DB, Surita FG. Self-concept and body image of people living with lupus: A systematic review. Int J Rheum Dis. 2021;00:1-15. https://doi.org/10.1111/1756-185X.14187 